\title{
Residual Capability of Alkali Binding by Hydrated Pozzolanic Cements in Long-Service Concrete Structures
}

\author{
Mario Berra $\left(\mathbb{D},{ }^{1}\right.$ Teresa Mangialardi $\left(\mathbb{D},{ }^{2}\right.$ and Antonio Evangelista Paolini ${ }^{2}$ \\ ${ }^{1}$ Ricerca sul Sistema Energetico (RSE) S.p.A., Via Rubattino 54, 20134 Milano, Italy \\ ${ }^{2}$ Department of Chemical Materials Environment Engineering, University "La Sapienza", \\ Via Eudossiana 18, 00184 Roma, Italy \\ Correspondence should be addressed to Mario Berra; mario.berra@rse-web.it
}

Received 25 October 2017; Accepted 29 April 2018; Published 4 June 2018

Academic Editor: Enzo Martinelli

Copyright (c) 2018 Mario Berra et al. This is an open access article distributed under the Creative Commons Attribution License, which permits unrestricted use, distribution, and reproduction in any medium, provided the original work is properly cited.

\begin{abstract}
An experimental procedure was developed and applied to cement pastes made with two different pozzolanic cements (CEM IV/B (P) and CEM IV/B (V)) in order to ascertain the existence of a residual capability of alkali binding by long-term hydrated pozzolanic cements and, at the same time, to evaluate the alkali retention capability and the concentration of $\mathrm{OH}^{-}$ions in the pore solution of such cementitious matrices. The developed procedure consisted of accelerated curing of cement paste specimens (150 days at $60^{\circ} \mathrm{C}$ and $\left.100 \% \mathrm{RH}\right)$, subsequent leaching tests at $60^{\circ} \mathrm{C}$ for 30 days by using deionized water or basic solutions $(\mathrm{NaOH}$ or $\mathrm{KOH}$ at different concentrations) as leaching media, and correlation of the leaching test results with a simple mass balance equation for sodium and potassium ions. The developed procedure was found to be appropriate for evaluating both the pore liquid alkalinity and the alkali retention capability by long-term hydrated pozzolanic cement pastes. A residual capability of alkali binding was also identified for both tested pozzolanic cements, thus indicating their potential ability to prevent (CEM IV/B (V)) or minimize $(\mathrm{CEM}$ IV/B $(\mathrm{P}))$ the risk of deleterious expansion associated with alkali-aggregate reaction in long-service concrete structures, like concrete dams.
\end{abstract}

\section{Introduction}

For long-service concrete structures, like concrete dams, the extension of lifetime, under appropriate safe conditions, is always a more frequent need. In this context, suitable monitoring activities together with diagnosis and prognosis analyses of the dam behaviour are required.

Delayed and progressive deformation of dams due to the expansive alkali-aggregate reaction (AAR) is often observed which gradually reduces the dam serviceability and even its structural safety $[1,2]$. For concrete dams containing alkali-reactive aggregates, independently of the cement alkali levels, long-term AAR expansion may be observed even after forty or more years from the dam construction. This expansive behaviour may be triggered by a long-term supply of alkalis due to slow alkali release from concrete aggregates and to alkali "recycling" from alkalisilica gel transformation $[2,3]$.
Of particular concern appears the amount of alkalis released from concrete aggregates that, according to laboratory leaching tests on aggregate samples, may significantly increase the alkali content of concrete $[4,5]$. However, there is, at present, no consensus on how to determine the alkali supply by aggregates $[6,7]$. Research on this subject is currently under way, and a new "releasable alkalis" test is being validated by RILEM [8].

Use of blended cements, especially pozzolanic cements, in the construction of concrete dams is generally considered as an effective measure for minimizing the risk of deleterious AAR expansion, thanks to the ability of their hydration products to incorporate most of the alkalis initially available in the pore solution of the cementitious matrix $[9,10]$. As a result, the alkalinity of the pore solution $\left(\mathrm{OH}^{-}\right.$ion concentration) will be significantly reduced. According to the recent RILEM guidelines [8], no case of damage by AAR has been to date reported for concrete dams containing high 
levels of good fly ash. In Italy, the use of pozzolanic cements made with natural pozzolana in the construction of concrete dams, a common local practice since the 1930s, appears, at least until now, to be effective in minimizing AAR expansion development [11].

In order to forecast the effectiveness of pozzolanic cements, even in the very long-term prevention of AAR, it is essential to verify if these cements are able to incorporate, besides the alkali already present and available in the concrete from the beginning, also those that may become available over time, after decades, due to the slow internal alkali supply. This eventual residual capability of alkali binding by pozzolanic cements approaching apparent ultimate hydration (apparently, complete cement hydration) is still unknown. The long-term expansion tests on concrete made with pozzolanic cements lasted at most for some years $[12,13]$, while many decades of experimentation would be needed for assessing the ability of such cements against AAR development, in the presence of new alkali supply. Whether or not such an alkali supply may overpower the residual capability of alkali binding by long-term hydrated pozzolanic cements is an important aspect that needs to be deeply analyzed.

The present study was specifically focused on this subject, trying to demonstrate indirectly that the pozzolanic cements are able to maintain their effectiveness, as a means to minimize AAR in concrete dams, even in the cases where alkalis are supplied over a very long time, during the dam service life.

To this aim, an experimental procedure was suitably developed and applied to cement pastes made with two types of pozzolanic cements containing natural pozzolana or coal fly ash in order to ascertain the existence of a residual capability of alkali binding by long-term hydrated pozzolanic cements. This procedure was also aimed at evaluating the alkali retention capability by long-term hydrated pozzolanic cements and the concentration of $\mathrm{OH}^{-}$ions in the pore solution of such cementitious matrices, both being taken as reference parameters to validate the appropriateness of the proposed methodology. According to this procedure, monolithic specimens of the cement paste were prepared and subjected to accelerated curing at $60^{\circ} \mathrm{C}$ in order to approach apparent ultimate cement hydration. Next, the hydrated cement pastes were subjected to leaching tests using deionized water or basic solutions $(\mathrm{NaOH}$ or $\mathrm{KOH}$ at different concentrations) as leaching media. Finally, the results of leaching tests were correlated with a simple mass balance equation for alkaline metal (sodium and potassium) ions.

\section{Theoretical Approach}

It is well known that long-term hydrated cement pastes are characterized by pore solutions that contain relatively high concentrations of $\mathrm{KOH}$ and $\mathrm{NaOH}$ as a result of the release of alkalis $\left(\mathrm{Na}_{2} \mathrm{O}\right.$ and $\left.\mathrm{K}_{2} \mathrm{O}\right)$ from cement and very low concentrations of calcium hydroxide, sulphate, and silicate. The $\mathrm{pH}$ of the pore solution is above 13.0 for Portland cement pastes and 11-11.5 for blended cement (Portland cement + supplementary cementing material (SCM)) pastes
[14]. The lower $\mathrm{pH}$ exhibited by blended cements is principally ascribed to a greater capability of alkali binding (adsorption/incorporation) by the reaction products formed during the hydration of blended cements. A dilution effect of alkalis by SCM additions in the blended cement formulation is also possible, especially in the case of blast furnace or slag cements.

When a monolithic specimen of the Portland or blended cement paste approaching apparent ultimate cement hydration (long-term hydrated cement paste) is put in contact with a leaching solution, such as deionized water or $\mathrm{NaOH}$ or $\mathrm{KOH}$ solution (leaching test), $\mathrm{Na}^{+}, \mathrm{K}^{+}$, and $\mathrm{OH}^{-}$ions and other minor ionic species $\left(\mathrm{Ca}^{+2}, \mathrm{SO}_{4}{ }^{-2}\right.$, and silicate) tend to flow from the pore solution of the cement paste to the leaching solution or vice versa. In the first case, there is ion release from cement paste; in the other case, there is ion accumulation within the pore solution. The flow direction depends on the leaching medium used and the concentration gradient established for the ionic species under consideration.

With reference to alkaline metals, the amount, $M_{\mathrm{r}}$, of sodium or potassium ions released or accumulated at the testing time, $t$, can be calculated by the following equation:

$$
M_{\mathrm{r}}=\frac{V_{\mathrm{L}}}{m_{0}}\left(C_{t}-C_{0}\right),
$$

where $M_{\mathrm{r}}$ is expressed in terms of moles of the metal released or accumulated $/ \mathrm{kg}$ of the cement paste, $m_{0}(\mathrm{~kg})$ is the mass of the cement paste subjected to the leaching test, $V_{\mathrm{L}}(\mathrm{l})$ is the volume of the leaching solution in contact with the monolithic specimen, $C_{0}(\mathrm{~mol} / \mathrm{l})$ is the initial concentration of the alkaline metal in the leaching solution, and $C_{t}(\mathrm{~mol} / \mathrm{l})$ is the concentration of the alkaline metal in the leaching solution at the time $t$.

For a testing time suitably long to approach equilibrium conditions, $C_{t}$ may be taken equal to $C_{\mathrm{eq}}$, the latter being the alkaline metal concentration at equilibrium in the leaching solution.

The $M_{\mathrm{r}}$ values calculated with (1) also correspond to the release or accumulation of alkalis in the form of $\mathrm{NaOH}$ (for sodium) and $\mathrm{KOH}$ (for potassium).

Assuming that equilibrium conditions are approached and there is no binding of alkaline metals by the solid phase of the cement paste, the following balance equation can be written, with reference to the alkaline metal under consideration:

$$
V_{\mathrm{L}} C_{0}+V_{\mathrm{p}} C_{\mathrm{p}}^{0}=C_{\mathrm{eq}}\left(V_{\mathrm{L}}+V_{\mathrm{p}}\right)
$$

where $C_{\mathrm{p}}^{0}(\mathrm{~mol} / \mathrm{l})$ is the concentration of the alkaline metal in the pore solution of the cementitious matrix before the leaching test, $V_{\mathrm{p}}(\mathrm{l})$ is the volume of the pore solution of the cementitious matrix, and the other terms are as previously defined.

The volume of the pore solution, $V_{\mathrm{p}}$, may be taken equal to

$$
V_{\mathrm{p}}=\alpha V_{\mathrm{m}} \text {, }
$$

where $\alpha$ and $V_{\mathrm{m}}$ (l) are, respectively, the open porosity and the volume of the monolithic specimen before the leaching test. 
Combining (2) and (3) yields

$$
\frac{C_{0}-C_{\mathrm{eq}}}{\alpha V_{\mathrm{m}}}=\frac{C_{0}}{V_{\mathrm{L}}+\alpha V_{\mathrm{m}}}-\frac{C_{\mathrm{p}}^{0}}{V_{\mathrm{L}}+\alpha V_{\mathrm{m}}} .
$$

Multiplying each member of (4) by the factor $V_{\mathrm{L}} / \rho_{\mathrm{ssd}}$, with $\rho_{\text {ssd }}(\mathrm{kg} / \mathrm{l})$ being the saturated surface-dry (ssd) density of the monolithic specimen of the cement paste, and rearranging the terms, (5) is obtained:

$$
\frac{V_{\mathrm{L}}\left(C_{0}-C_{\mathrm{eq}}\right)}{\rho_{\mathrm{ssd}} V_{\mathrm{m}}}=\frac{\alpha V_{\mathrm{L}} C_{0}}{\rho_{\text {ssd }}\left(V_{\mathrm{L}}+\alpha V_{\mathrm{m}}\right)}-\frac{\alpha V_{\mathrm{L}} C_{\mathrm{p}}^{0}}{\rho_{\mathrm{ssd}}\left(V_{\mathrm{L}}+\alpha V_{\mathrm{m}}\right)}
$$

The first member of this equation represents the amount of the alkaline metal (sodium or potassium) released or accumulated per unit weight of the cement paste and corresponds to $M_{\mathrm{r}}$, as defined by (1).

Therefore, according to (5), there is a linear relationship between $M_{\mathrm{r}}$ and $C_{0}$. The intercept of the straight line with the $x$-axis stands for $C_{\mathrm{p}}^{0}$, that is, the concentration of the alkaline metal in the pore solution of the cementitious matrix before the leaching test. Besides, the intercept of the straight line with the $y$-axis $\left(C_{0}=0\right)$ stands for the release of the alkaline metal in deionized water, $M_{\mathrm{r}}^{\mathrm{H}}$ (moles of the metal per $\mathrm{kg}$ of the cement paste):

$$
M_{\mathrm{r}}^{\mathrm{H}}=\frac{\alpha V_{\mathrm{L}} C_{\mathrm{p}}^{0}}{\rho_{\mathrm{ssd}}\left(V_{\mathrm{L}}+\alpha V_{\mathrm{m}}\right)} .
$$

Thus, for example, the concentration of potassium ions in the pore solution of a long-term hydrated cement paste, $\left(C_{\mathrm{p}}^{0}\right)^{\mathrm{K}}$, can be identified as the value of the initial molar concentration of $\mathrm{KOH}$ in the leaching solution, $C_{0}^{\mathrm{K}}$, for which $M_{\mathrm{r}}=0$; that is, no release or accumulation of potassium is detected.

If the accumulation of alkaline metals occurring for $C_{0}>C_{\mathrm{p}}^{0}$ is also accompanied by metal binding, then the obtained $M_{\mathrm{r}}$ value (negative) will be, in absolute value, higher than the one predicted by (5). The extent of deviation from linearity may be taken as a measure of the amount of the alkaline metal, and hence the amount of alkalis $(\mathrm{KOH}$ or $\mathrm{NaOH})$, bound by the cementitious matrix.

\section{Materials and Methods}

Two commercial pozzolanic cements CEM IV/B 32.5R conforming to UNI EN 197-1 [15] and marked as CEM IV/B (P) and CEM IV/B (V) were selected for this study: the first one contained $35 \mathrm{wt}$.\% of natural pozzolana, while the other contained 35 wt.\% of coal fly ash. These two cements were analysed for their chemical composition by using the X-ray fluorescence (XRF) technique for major elements. The content of alkaline metals ( $\mathrm{Na}$ and $\mathrm{K}$ ) was determined by atomic absorption spectrophotometry (AAS) on the liquid sample resulting from cement dissolution with $\mathrm{HCl}$ (UNI EN 196-2) [16]. Loss on ignition (LOI) was determined according to UNI EN 196-2. The chemical compositions of the two pozzolanic cements, expressed in terms of oxide components, are reported in Table 1. Table 2 gives the chemical compositions of natural pozzolana and coal fly ash
TABLE 1: Chemical compositions of the two pozzolanic cements.

\begin{tabular}{lcc}
\hline Oxide (wt.\%) & CEM IV/B (P) & CEM IV/B (V) \\
\hline $\mathrm{SiO}_{2}$ & 27.78 & 30.69 \\
$\mathrm{Al}_{2} \mathrm{O}_{3}$ & 8.18 & 11.17 \\
$\mathrm{Fe}_{2} \mathrm{O}_{3}$ & 5.27 & 5.24 \\
$\mathrm{CaO}$ & 44.67 & 42.68 \\
$\mathrm{MgO}$ & 2.75 & 1.46 \\
$\mathrm{SO}_{3}$ & 2.69 & 2.63 \\
$\mathrm{~K}_{2} \mathrm{O}$ & 2.93 & 1.35 \\
$\mathrm{Na}_{2} \mathrm{O}$ & 0.41 & 0.19 \\
$\mathrm{Na}_{2} \mathrm{Oeq}$ & 2.34 & 1.08 \\
$\mathrm{LOI}$ & 2.53 & 3.12 \\
Total & 97.21 & 98.53 \\
\hline
\end{tabular}

TABle 2: Chemical compositions of natural pozzolana and coal fly ash.

\begin{tabular}{lcc}
\hline Oxide (wt.\%) & Natural pozzolana & Fly ash \\
\hline $\mathrm{SiO}_{2}$ & 40.77 & 49.37 \\
$\mathrm{Al}_{2} \mathrm{O}_{3}$ & 20.41 & 29.23 \\
$\mathrm{Fe}_{2} \mathrm{O}_{3}$ & 2.85 & 1.59 \\
$\mathrm{CaO}$ & 13.02 & 6.63 \\
$\mathrm{SO}_{3}$ & 0.55 & 0.33 \\
$\mathrm{~K}_{2} \mathrm{O}$ & 6.55 & 2.12 \\
$\mathrm{Na}_{2} \mathrm{O}$ & 0.67 & 0.05 \\
$\mathrm{Na}_{2} \mathrm{Oeq}$ & 4.99 & 1.45 \\
$\mathrm{LOI}$ & 4.17 & 4.82 \\
\hline
\end{tabular}

used in the blended cement formulations, as declared by the producer.

Cement pastes were prepared using each pozzolanic cement and deionized water (electrical conductivity $<4 \mu \mathrm{S} / \mathrm{cm}$ ) as mixing water. The water/cement weight $(\mathrm{w} / \mathrm{c})$ ratio of the pozzolanic cement pastes was 0.40 . Each mixture was prepared by a mechanical mixer and used to produce cubic specimens ( $4 \mathrm{~cm}$ side) in specific moulds. After 1 day of curing within the moulds at $20 \pm 2^{\circ} \mathrm{C}$ and $\mathrm{RH}>95 \%$, the specimens were demoulded and placed in tightly sealed inox steel containers, with enough deionized water, at their bottom, to produce $100 \% \mathrm{RH}$ environment. The containers were then stored in a thermostatically controlled laboratory oven at a temperature of $60 \pm 2^{\circ} \mathrm{C}$ for 150 days (accelerated curing).

At different curing times, some specimens were removed from the containers and characterized for their hydration degree through the determinations of chemically bound water and portlandite $\left(\mathrm{Ca}(\mathrm{OH})_{2}\right)$ contents. To this aim, each specimen was preliminarily grounded to fineness below $45 \mu \mathrm{m}$ and was treated with acetone and ethyl ether in order to remove the amount of free water. The resulting powder was then analysed by simultaneous thermogravimetric analysis (TGA) and differential scanning calorimetry (DSC) in static air at a heating rate of $10^{\circ} \mathrm{C} / \mathrm{min}$.

The content of chemically bound water, $W_{\mathrm{b}}$, was determined from the weight loss recorded on TGA thermogram between 105 and $1000^{\circ} \mathrm{C}$, according to the procedure proposed by Monteagudo et al. [17]. This procedure is based on the combination of different contributions by hydrated cement phases: dehydration, dehydroxylation, and decarbonation, the 
last being related to carbonated portlandite. The weight loss of anhydrous blended cement over the whole temperature range considered is also taken into account. The amount of portlandite was determined from the weight loss between 400 and $450^{\circ} \mathrm{C}$ on TGA thermogram, corresponding to the endothermic peak of $\mathrm{Ca}(\mathrm{OH})_{2}$ dehydration on DSC thermogram (dehydroxylation).

At the end of the accelerated curing (150 days), a series of specimens were subjected to water absorption tests in order to evaluate the density, $\rho_{\text {ssd }}$, and the open porosity, $\alpha$, of the monolithic specimens. To this aim, the specimens were preliminarily oven-dried at $60^{\circ} \mathrm{C}$ to constant weight, then submerged in deionized water for 24 hours, and finally dried out sufficiently to reach the "saturated surface-dry (ssd)" condition ready for the final weighing.

Another series of specimens were subjected to leaching tests by using $\mathrm{NaOH}$ or $\mathrm{KOH}$ solutions at different concentrations or deionized water (designated as $\mathrm{H}$ ) as leaching media. The caustic solutions were prepared by dissolving appropriate amounts of analytical-grade pure metal hydroxide in deionized water. Table 3 gives the concentrations $(\mathrm{mol} / \mathrm{l})$ of $\mathrm{KOH}\left(C_{0}^{\mathrm{K}}\right)$ or $\mathrm{NaOH}\left(C_{0}^{\mathrm{N}}\right)$ solutions, along with the designations of these solutions: from N1 to N6 for sodium hydroxide and from $\mathrm{K} 1$ to $\mathrm{K} 6$ for potassium hydroxide.

For each leaching test, one cubic specimen $\left(V_{\mathrm{m}}=0.064 \mathrm{l}\right)$ was submerged in 0.1501 of leaching solution (liquid/solid ratio $=2.34$ in volume) in a tightly sealed polypropylene container, arranging the specimen in a raised position with respect to the container's bottom. Each container was tightly closed and stored in an oven at $60^{\circ} \mathrm{C}$ for a testing period of 30 days, after which an aliquot of the leaching solution was analyzed for the concentrations of $\mathrm{Na}^{+}$and $\mathrm{K}^{+}$ions by means of AAS. The same determinations were also carried out on the leaching solutions before testing. Three replicate leaching tests were performed for each long-term hydrated cement paste, and the results were averaged.

\section{Results and Discussion}

4.1. Hydration Kinetics of Cement Pastes. Figure 1 shows the hydration kinetics of cement pastes made with CEM IV/B $(\mathrm{P})$ or $\mathrm{CEM}$ IV/B $(\mathrm{V})(\mathrm{w} / \mathrm{c}$ ratio $=0.40)$ cured at $60^{\circ} \mathrm{C}$ and $100 \% \mathrm{RH}$. In particular, the chemically bound water content, $W_{\mathrm{b}}$ (g of $\mathrm{H}_{2} \mathrm{O} / 100 \mathrm{~g}$ of the ignited cement paste), is shown plotted against the curing time, $t$ (days).

As expected, under the above curing conditions, both pozzolanic cements hydrated rapidly and, after about 28 days, the $W_{\mathrm{b}}$ content levelled off. At the end of the curing period (150 days), the $W_{\mathrm{b}}$ values resulted to be 19.2 and $20.6 \mathrm{~g}$ of $\mathrm{H}_{2} \mathrm{O} / 100 \mathrm{~g}$ of the ignited cement paste for CEM IV/B (P) and CEM IV/B (V), respectively.

Similarly, the kinetics of portlandite consumption (not reported here) showed that the content of portlandite in cement pastes decreased rapidly with increasing curing time and levelled off after about 28 days. At the end of the curing period, the $\mathrm{Ca}(\mathrm{OH})_{2}$ content resulted to be 5.2 and $4.3 \mathrm{~g} / 100 \mathrm{~g}$ of the cement paste for CEM IV/B (P) and CEM IV/B (V), respectively. These data revealed good pozzolanic
TABle 3: Composition of the basic leaching solutions and their designation.

\begin{tabular}{lccc}
\hline $\begin{array}{l}\text { Leaching } \\
\text { medium }\end{array}$ & $\begin{array}{c}\mathrm{NaOH} \\
(\mathrm{mol} / \mathrm{l})\end{array}$ & $\begin{array}{c}\text { Leaching } \\
\text { medium }\end{array}$ & $\begin{array}{c}\mathrm{KOH} \\
(\mathrm{mol} / \mathrm{l})\end{array}$ \\
\hline N1 & 0.034 & $\mathrm{~K} 1$ & 0.020 \\
N2 & 0.072 & $\mathrm{~K} 2$ & 0.042 \\
N3 & 0.110 & $\mathrm{~K} 3$ & 0.087 \\
N4 & 0.148 & $\mathrm{~K} 4$ & 0.193 \\
N5 & 0.153 & $\mathrm{~K} 5$ & 0.374 \\
N6 & 0.219 & $\mathrm{~K} 6$ & 0.723 \\
\hline
\end{tabular}

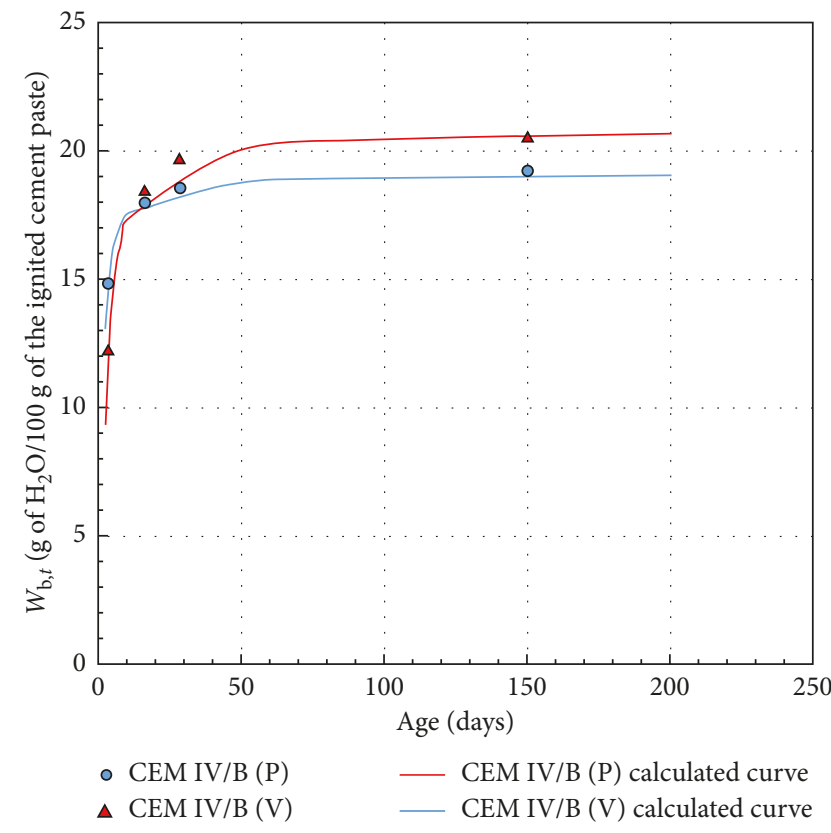

Figure 1: Hydration kinetics of the cement pastes investigated.

activities for both SCMs (natural pozzolana and fly ash) used in the formulation of the two cements investigated.

The hydration degree of the cement pastes at a given curing time, $\alpha_{\mathrm{t}} \%$, was calculated as follows:

$$
\alpha_{\mathrm{t}} \%=\frac{W_{\mathrm{b}, \mathrm{t}}}{W_{\mathrm{b}, \infty}} \cdot 100,
$$

where $W_{\mathrm{b}, \mathrm{t}}$ is the chemically bound water content at the time $t$ and $W_{\mathrm{b}, \infty}$ is the chemically bound water content in accordance with the apparent ultimate cement hydration under the designed curing conditions $\left(60^{\circ} \mathrm{C}\right.$ and $100 \% \mathrm{RH}$ in this study).

According to the procedure developed by Monteagudo et al. [17], the value of $W_{\mathrm{b}, \infty}$ was calculated by using the following Michaelis-Menten-type equation:

$$
W_{\mathrm{b}, \mathrm{t}}=W_{\mathrm{b}, \infty} \frac{t}{t+K}
$$

where $K$ is the half-velocity constant (defined as the value of $t$ for which $\left.W_{\mathrm{b}, \mathrm{t}}=(1 / 2) W_{\mathrm{b}, \infty}\right)$, and the other terms are as previously defined.

The parameters $W_{\mathrm{b}, \infty}$ and $K$ were obtained by correlating the experimental results of Figure 1 with (8) in the 


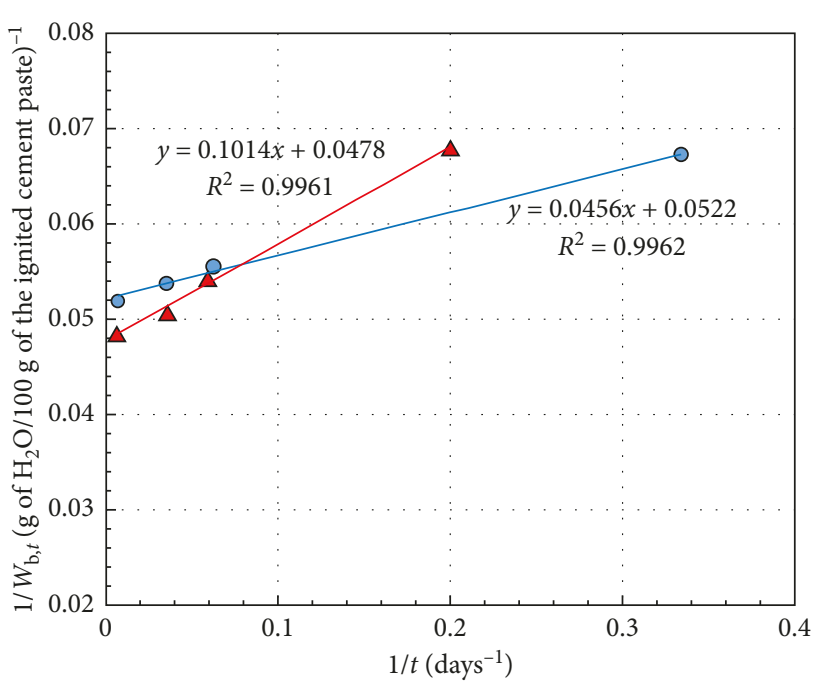

- $\mathrm{CEM}$ IV/B (P)

$\triangle \mathrm{CEM}$ IV/B (V)

Figure 2: Correlation of experimental hydration data with (8).

TABLe 4: Values of $W_{\mathrm{b}, \infty}, K$, and $\alpha_{150} \%$ for the two types of cement pastes.

\begin{tabular}{lcc}
\hline & CEM IV/B (P) & CEM IV/B (V) \\
\hline$W_{\mathrm{b}, \infty}\left(\mathrm{g}\right.$ of $\mathrm{H}_{2} \mathrm{O} / 100 \mathrm{~g}$ of the & 19.16 & 20.92 \\
ignited cement paste) & 0.87 & 2.12 \\
$K$ (days) & 100 & 98.38 \\
$\alpha_{150} \%$ & \\
\hline
\end{tabular}

linearized Lineweaver-Burk form $\left(1 / W_{\mathrm{b}, \mathrm{t}}\right.$ versus $\left.1 / t\right)$. Such a correlation for each type of the cement paste is shown in Figure 2.

As evidenced by the values of the determination coefficient, $R^{2}$, a good correlation of experimental hydration data with (8) was obtained for both types of cement. Thus, the parameter $W_{\mathrm{b}, \infty}$ was calculated from the intercept $\left(1 / W_{\mathrm{b}, \infty}\right)$ of the straight line with the $y$-axis, while $K$ was calculated from the slope $\left(K / W_{\mathrm{b}, \infty}\right)$ of this line. The values of $W_{\mathrm{b}, \infty}$ and $K$ were used to draw the hydration curves shown in Figure 1.

Equation (7) was then used to calculate the hydration degree of the cement pastes at the end of the curing period $\left(\alpha_{150} \%\right)$. The values of $W_{\mathrm{b}, \infty}, K$, and $\alpha_{150} \%$ for the two types of cement pastes are given in Table 4.

The $W_{\mathrm{b}, \infty}$ values were congruent with those reported in the literature for blended cements [18].

The $\alpha_{150} \%$ values indicated that the monolithic specimens of the cement paste, to be subjected to leaching tests, exhibited apparent ultimate cement hydration (apparently, complete cement hydration) under the curing conditions adopted in this study.

4.2. Leaching Tests. Table 5 gives the concentrations ( $\mathrm{mol} / \mathrm{l}$ ) of sodium and potassium ions measured in the solutions from N1 to N6 and from K1 to K6 after 30 days of immersion of the monolithic specimens at $60^{\circ} \mathrm{C}$. In this table, the results
TABLE 5: Results of leaching tests on monolithic specimens of hydrated cement pastes.

\begin{tabular}{lcccc}
\hline \multirow{2}{*}{$\begin{array}{l}\text { Cement } \\
\text { Leaching medium }\end{array}$} & \multicolumn{2}{c}{ CEM IV/B (P) } & \multicolumn{2}{c}{ CEM IV/B (V) } \\
\hline H & 0.015 & 0.048 & 0.010 & 0.020 \\
N1 & 0.046 & 0.051 & 0.041 & 0.018 \\
N2 & 0.077 & 0.039 & 0.076 & 0.019 \\
N3 & 0.112 & 0.043 & 0.103 & 0.020 \\
N4 & 0.140 & 0.041 & 0.137 & 0.021 \\
N5 & 0.140 & 0.043 & 0.141 & 0.021 \\
N6 & 0.170 & 0.046 & 0.162 & 0.022 \\
K1 & 0.026 & 0.071 & 0.015 & 0.036 \\
K2 & 0.029 & 0.084 & 0.015 & 0.056 \\
K3 & 0.028 & 0.123 & 0.014 & 0.099 \\
K4 & 0.019 & 0.218 & 0.008 & 0.198 \\
K5 & 0.019 & 0.379 & 0.009 & 0.327 \\
K6 & 0.019 & 0.672 & 0.009 & 0.621 \\
\hline
\end{tabular}

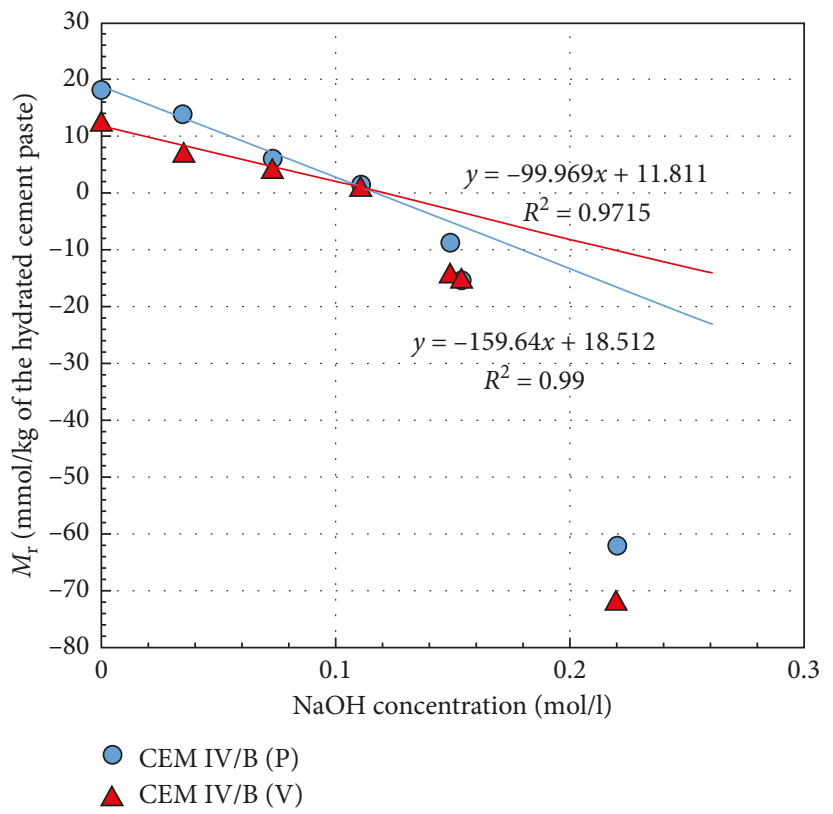

Figure 3: Relationship between $M_{\mathrm{r}}$ and $C_{0}$ for sodium.

of the leaching tests using deionized water $(\mathrm{H})$ as a leaching medium are also reported.

The experimental values of $M_{\mathrm{r}}$ for the two alkaline metals were calculated in terms of mmol of the metal per $\mathrm{kg}$ of the cement paste by using (1), the data of Tables 3 and 5, together with the mass $\left(m_{0}\right)$ of the monolithic specimen appositely weighted before the leaching test, and the volume $\left(V_{\mathrm{L}}\right)$ of leaching solution.

Figure 3 shows the experimental $M_{\mathrm{r}}$ values for sodium plotted as a function of the initial concentration of $\mathrm{NaOH}$, $C_{0}^{\mathrm{N}}$, in the leaching solution. The corresponding plot for potassium is shown in Figure 4.

As can be noted, the release of alkaline metals $\left(M_{\mathrm{r}}>0\right)$ may be successfully correlated with the initial concentration, $C_{0}$, of the metal in the leaching solution through (5) and, as expected, $M_{\mathrm{r}}$ decreased with increasing $C_{0}$. The mathematical relationships obtained using only the positive values 


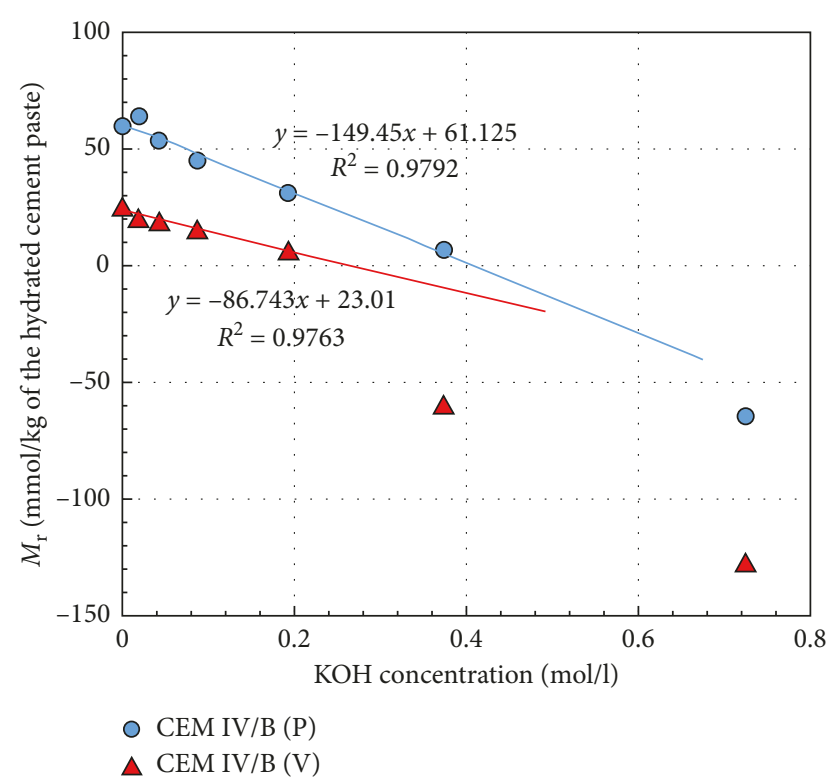

Figure 4: Relationship between $M_{\mathrm{r}}$ and $C_{0}$ for potassium.

of $M_{\mathrm{r}}$ are reported in abovementioned figures, along with the corresponding determination coefficients, $R^{2}$.

For the leaching solutions with higher concentrations of $\mathrm{NaOH}(\mathrm{N} 4, \mathrm{~N} 5$, and N6) or $\mathrm{KOH}$ (K5 only for CEM IV/B (V) and K6), the experimental data (negative values of $M_{\mathrm{r}}$ ) fell below the regression lines, thus indicating the existence of more or less significant deviation from the linearity predicted by (5). It should be recalled that this equation does not take account of the amount of alkaline metals bound (by adsorption/incorporation) by the solid phase of the cement paste (Section 2).

Therefore, the deviation from linearity can be considered as an index of metal binding by the cementitious matrix and, accordingly, the extent of such a deviation was used to calculate the amount of the alkaline metal, sodium or potassium, bound by long-term hydrated CEM IV/B (P) or $\mathrm{CEM}$ IV/B (V) pastes. The intercept of the straight regression lines with the $x$-axis (Figures 3 and 4 ) allowed the calculation of alkaline metal concentrations in the pore solution of each cement paste before leaching tests.

Even if limited to two types of pozzolanic cements, the elaboration of the leaching data through (5) provided useful information about

(1) the suitability of the experimental procedure adopted for the evaluation of the alkali concentration in the pore solution of long-term hydrated cementitious matrices;

(2) the validity of (6) to predict the release of alkaline metals in deionized water $\left(M_{\mathrm{r}}^{\mathrm{H}}\right)$ and thus the retention capability of such metals by long-term hydrated pozzolanic cements;

(3) the existence of a residual capability of alkali binding by long-term hydrated pozzolanic cements and its significance in relation to long-term release of alkalis from aggregates in long-service concrete structures, particularly in concrete dams.
These items are specifically examined and discussed in the following three sections.

4.2.1. Evaluation of the Hydroxyl Ion Concentration in the Pore Solution of Cementitious Matrices. The concentrations of sodium and potassium ions (and hence concentrations of $\mathrm{NaOH}$ and $\mathrm{KOH}$ ) in the pore solutions of the tested cementitious matrices were calculated from Figures 3 and 4 and resulted to be $\left(C_{\mathrm{p}}^{0}\right)^{\mathrm{Na}}=0.116 \mathrm{~mol} / \mathrm{l}$ and $\left(C_{\mathrm{p}}^{0}\right)^{\mathrm{K}}=0.409 \mathrm{~mol} / \mathrm{l}$ for the cement paste made with $\mathrm{CEM}$ IV/B (P) and $\left(C_{\mathrm{p}}^{0}\right)^{\mathrm{Na}}=0.118 \mathrm{~mol} / \mathrm{l}$ and $\left(C_{\mathrm{p}}^{0}\right)^{\mathrm{K}}=0.265 \mathrm{~mol} / \mathrm{l}$ for $\mathrm{CEM} \mathrm{IV} / \mathrm{B}$ (V) paste.

The $C_{\mathrm{p}}^{0}$ values obtained for sodium were similar, in spite of the higher $\mathrm{Na}_{2} \mathrm{O}$ content of cement CEM IV/B (P) compared to CEM IV/B (V) (Table 1 ). The two $C_{\mathrm{p}}^{0}$ values for potassium were, on the contrary, considerably different, with the higher value being associated with CEM IV/B (P). This matched with the higher $\mathrm{K}_{2} \mathrm{O}$ content of this cement (Table 1).

The concentration of the $\mathrm{OH}^{-}$ions $(\mathrm{mol} / \mathrm{l})$ in the pore solution of each cement paste was calculated by summing the above values of $\left(C_{\mathrm{p}}^{0}\right)^{\mathrm{Na}}$ and $\left(C_{\mathrm{p}}^{0}\right)^{\mathrm{K}}$ for the considered cement paste. $\mathrm{OH}^{-}$ion concentrations of 0.525 and $0.383 \mathrm{~mol} / \mathrm{l}$ were obtained for CEM IV/B (P) and CEM IV/B (V) pastes, respectively.

These $\mathrm{OH}^{-}$ion concentrations were compared to those discussed in a recent review paper [19] concerning blended cement pastes, where most of the data presented were obtained by pore liquid expression of hardened specimens. Unfortunately, in this review, as well as in other literature works on this subject, no experimental data were available regarding the chemical composition of the pore solution of blended cement pastes containing natural pozzolana. Therefore, the comparison was restricted to CEM IV/B (V) pastes, for which a consistency was found between the $\mathrm{OH}^{-}$ ion concentration value of the present study $(0.383 \mathrm{~mol} / \mathrm{l})$ and those (0.3-0.4 mol/l) reported for blended cement pastes made with $30-40$ wt. $\%$ coal fly ash, w/c ratio $=0.40$, and different alkali contents of binder [19, 20].

This suggested that the procedure developed in the present study could also be adopted as a tool for estimating the concentration of alkalis in the pore solution of long-term hydrated cementitious matrices.

Although the $\mathrm{OH}^{-}$ion concentration for CEM IV/B (P) pastes was higher than that evaluated for CEM IV/B (V) pastes, it was significantly lower than the $\mathrm{OH}^{-}$ion concentrations $(0.7-0.9 \mathrm{~mol} / \mathrm{l})$ reported in the literature for high-alkali Portland cement pastes $[19,20]$. This revealed a good capability of natural pozzolana in reducing the alkalinity of the pore solution of cement pastes containing such an SCM.

4.2.2. Retention Capability of Alkaline Metals by Long-Term Hydrated Pozzolanic Cement Pastes. Table 6 compares the amounts of alkaline metals ( $\mathrm{mmol} / \mathrm{kg}$ of the cement paste) released in deionized water (experimental $M_{\mathrm{r}}^{\mathrm{H}}$ values) with those predicted from (6) using the $C_{\mathrm{p}}^{0}$ values reported in the previous section and the values of porosity $(\alpha)$ and density 
TABLe 6: Predicted and experimental $M_{\mathrm{r}}$ values and retention capabilities of $\mathrm{Na}^{+}$and $\mathrm{K}^{+}$ions by hydrated cement pastes.

\begin{tabular}{lccccccc}
\hline \multirow{2}{*}{ Leaching medium } & \multicolumn{4}{c}{ CEM IV/B (P) } & \multicolumn{3}{c}{ CEM IV/B (V) } \\
& & $\mathrm{H}$ & $\mathrm{K} 6$ & $\mathrm{~N} 6$ & $\mathrm{H}$ & $\mathrm{K} 6$ & $\mathrm{~N} 6$ \\
\hline \multirow{2}{*}{$M_{\mathrm{r}, \exp }(\mathrm{mmol} / \mathrm{kg})$} & $\mathrm{Na}$ & 18.3 & 15.2 & - & 12.6 & 13.0 & - \\
\multirow{2}{*}{$M_{\mathrm{r}, \mathrm{pr}}(6)(\mathrm{mmol} / \mathrm{kg})$} & $\mathrm{K}$ & 59.7 & - & 64.1 & 24.6 & - & 27.9 \\
& $\mathrm{Na}$ & 15.1 & - & - & 13.9 & - & - \\
$R_{\mathrm{p}} \%$ & $\mathrm{~K}$ & 51.0 & - & - & 30.5 & - & - \\
& $\mathrm{Na}$ & 80.6 & 83.7 & - & 71.6 & 70.5 & - \\
& $\mathrm{K}$ & 86.6 & - & 85.6 & 88.0 & - & 86.4 \\
\hline
\end{tabular}

$\left(\rho_{\text {ssd }}\right)$ of the monolithic specimens, measured before the leaching tests $\left(\alpha=0.276\right.$ and $\rho_{\text {ssd }}=1.974 \mathrm{~kg} / \mathrm{l}$ for CEM IV $/ \mathrm{B}$ (P) paste; $\alpha=0.248$ and $\rho_{\text {ssd }}=1.950 \mathrm{~kg} / \mathrm{l}$ for CEM IV $/ \mathrm{B}(\mathrm{V})$ paste).

Table 6 also includes the percentage retention capability $\left(R_{\mathrm{p}} \%\right)$ of alkaline metals by long-term hydrated cement pastes, when put in contact with different leaching media: deionized water $(\mathrm{H})$ for both sodium and potassium retention, $\mathrm{KOH}$ solution with the highest concentration (K6) for sodium retention, and $\mathrm{NaOH}$ solution with the highest concentration (N6) for potassium retention. The $R_{\mathrm{p}} \%$ values were calculated as $100^{*}\left(M_{\mathrm{in}}-M_{\mathrm{r}}\right) / M_{\mathrm{in}}$, where $M_{\mathrm{r}}$ $(\mathrm{mmol} / \mathrm{kg}$ of the cement paste) is the metal release determined experimentally and $M_{\text {in }}(\mathrm{mmol} / \mathrm{kg})$ is the initial metal content per unit weight of the cement paste, the latter being obtained on the basis of the cement paste composition $(\mathrm{w} / \mathrm{c}$ ratio $=0.40)$ and the cement alkali content (Table 1$)$. The values of $M_{\text {in }}$ resulted to be $94.3 \mathrm{mmol}$ of $\mathrm{Na} / \mathrm{kg}$ of the cement paste and $445.4 \mathrm{mmol}$ of $\mathrm{K} / \mathrm{kg}$ of the cement paste for CEM IV/B (P) and $43.9 \mathrm{mmol}$ of $\mathrm{Na} / \mathrm{kg}$ of the cement paste and $205.1 \mathrm{mmol}$ of $\mathrm{K} / \mathrm{kg}$ of the cement paste for CEM IV/B (V).

It can be observed from Table 6 that the experimental values of $M_{\mathrm{r}}^{\mathrm{H}}$ were in good agreement with those predicted from (6), thus proving the validity of this equation and, more in general, of (5).

Both the long-term hydrated pozzolanic cements were characterized by high retention capabilities of potassium $\left(R_{\mathrm{p}} \%=87-88 \%\right)$, when put in contact with deionized water. The retention capabilities of sodium were also considerable $\left(R_{\mathrm{p}} \%=72-81 \%\right)$, even if slightly lower as compared to potassium. These results were consistent with those reported by Bach et al. [14] for hydrated low-pH cements. As shown in Table 6 , the $R_{\mathrm{p}} \%$ values did not significantly change if the basic solution N6 (for potassium) and K6 (for sodium) were used as leaching media in place of deionized water.

\subsubsection{Residual Capability of Alkali Binding by Long-Term} Hydrated Pozzolanic Cement Pastes. The experimental $M_{\mathrm{r}}$ values obtained for sodium and potassium ions $(\mathrm{mmol} / \mathrm{kg}$ of the cement paste) in the various leaching media were compared in Tables 7 and 8 with those calculated using the linear regression equations of Figures 3 and 4 . The difference between the negative values of experimental and calculated $M_{\mathrm{r}}$ was taken as a measure of the amount of the alkaline metal bound by the cementitious matrix and was indicated
TABLE 7: Experimental and calculated $M_{\mathrm{r}}$ values for sodium and corresponding $M_{\mathrm{b}}$ values.

\begin{tabular}{lcccccc}
\hline Leaching & \multicolumn{3}{c}{ CEM IV/B (P) } & \multicolumn{3}{c}{ CEM IV/B (V) } \\
medium & $M_{\mathrm{r}, \exp }$ & $M_{\mathrm{r}, \mathrm{calc}}$ & $M_{\mathrm{b}}$ & $M_{\mathrm{r}, \exp }$ & $M_{\mathrm{r}, \mathrm{calc}}$ & $M_{\mathrm{b}}$ \\
\hline $\mathrm{H}$ & 18.26 & 18.70 & - & 12.61 & 11.74 & - \\
N1 & 13.91 & 13.04 & - & 7.39 & 8.26 & - \\
N2 & 6.09 & 6.96 & - & 4.35 & 4.78 & - \\
N3 & 1.30 & 0.87 & - & 1.30 & 0.87 & - \\
N4 & -8.70 & -6.96 & 1.74 & -13.91 & -2.61 & 11.30 \\
N5 & -15.22 & -6.09 & 9.13 & -14.78 & -3.48 & 11.30 \\
N6 & -62.17 & -16.52 & 45.65 & -71.74 & -10.00 & 61.74 \\
\hline
\end{tabular}

TABLE 8: Experimental and calculated $M_{\mathrm{r}}$ values for potassium and corresponding $M_{\mathrm{b}}$ values.

\begin{tabular}{lcccccc}
\hline \multirow{2}{*}{$\begin{array}{l}\text { Leaching } \\
\text { medium }\end{array}$} & \multicolumn{3}{c}{ CEM IV/B (P) } & \multicolumn{3}{c}{ CEM IV/B (V) } \\
\hline H & $M_{\mathrm{r} \text { exp }}$ & $M_{\mathrm{r}, \mathrm{calc}}$ & $M_{\mathrm{b}}$ & $M_{\mathrm{r}, \exp }$ & $M_{\mathrm{r}, \mathrm{calc}}$ & $M_{\mathrm{b}}$ \\
K1 & 59.74 & 61.03 & - & 24.62 & 23.08 & - \\
K2 & 63.85 & 58.21 & - & 20.26 & 21.28 & - \\
K3 & 53.59 & 54.87 & - & 18.72 & 19.49 & - \\
K4 & 45.13 & 48.21 & - & 15.13 & 15.38 & - \\
K5 & 31.03 & 32.31 & - & 6.67 & 6.15 & - \\
K6 & 6.41 & 5.13 & - & -59.49 & -9.49 & 50.00 \\
\hline
\end{tabular}

as $M_{\mathrm{b}}\left(\mathrm{mmol} / \mathrm{kg}\right.$ of the cement paste). Thus, the value of $M_{\mathrm{b}}$ also provided the residual capability of alkali $(\mathrm{KOH}$ or $\mathrm{NaOH}$ ) binding by long-term hydrated pozzolanic cements, in accordance with the initial concentration, $C_{0}^{\mathrm{K}}$ or $C_{0}^{\mathrm{N}}$, considered.

The obtained $M_{\mathrm{b}}$ values indicated that, with respect to CEM IV/B (P), CEM IV/B (V) had a higher binding capability for sodium $\left(M_{\mathrm{b}}=61.74 \mathrm{mmol} / \mathrm{kg}\right.$ against $45.65 \mathrm{mmol} / \mathrm{kg}$ for $\left.C_{0}^{\mathrm{N}}=0.219 \mathrm{~mol} / \mathrm{l}\right)$ and, even more, for potassium $\left(M_{\mathrm{b}}=87.44 \mathrm{mmol} / \mathrm{kg}\right.$ against $16.93 \mathrm{mmol} / \mathrm{kg}$ for $\left.C_{0}^{\mathrm{K}}=0.723 \mathrm{~mol} / \mathrm{l}\right)$.

Moreover, for CEM IV/B (V), the binding capability for potassium was well higher than that evaluated for sodium, and this could be ascribed to the higher difference $\left(C_{0}^{\mathrm{K}}-\left(C_{\mathrm{p}}^{0}\right)^{\mathrm{K}}\right)$ (driving force for metal mass transfer) as compared to $\left(C_{0}^{\mathrm{N}}-\left(C_{\mathrm{p}}^{0}\right)^{\mathrm{Na}}\right)$. However, for CEM IV/B (P), an opposite result was found $\left(M_{\mathrm{b}}=16.93 \mathrm{mmol}\right.$ of $\mathrm{K} / \mathrm{kg}$ against $45.65 \mathrm{mmol}$ of $\mathrm{Na} / \mathrm{kg}$ of the cement paste).

The $M_{\mathrm{b}}$ values were also related to the amount of alkalis released from aggregates of Italian origin [5], when subjected to leaching tests with $0.7 \mathrm{M} \mathrm{NaOH}$ or $\mathrm{KOH}$ solutions at $80^{\circ} \mathrm{C}$, according to a test method proposed by Bérubé et al. [4]. The maximum amount of sodium and potassium released was found to be $0.22 \mathrm{~g}$ of Na/ $\mathrm{kg}$ of the fine aggregate and $0.086 \mathrm{~g}$ of $\mathrm{K} / \mathrm{kg}$ of the fine aggregate, corresponding to percentage releases of $4.40 \%$ for $\mathrm{Na}$ and $1.72 \%$ for $\mathrm{K}$. For the coarse grain size of the same aggregate, the sodium and potassium released were $0.068 \mathrm{~g}$ of $\mathrm{Na} / \mathrm{kg}$ and $0.07 \mathrm{~g}$ of $\mathrm{K} / \mathrm{kg}$, corresponding to percentage releases of $1.36 \%$ for $\mathrm{Na}$ and $1.40 \%$ for $\mathrm{K}$.

On the basis of the amounts of alkaline metals released from the considered aggregate (reference aggregate) and 
referring to a typical dam concrete composition $\left(200 \mathrm{~kg} / \mathrm{m}^{3}\right.$ of Portland cement; $2100 \mathrm{~kg} / \mathrm{m}^{3}$ of aggregates, of which $35 \%$ were with fine grain size and $65 \%$ with coarse grain size; w/c ratio $=0.6$ ), a supply of alkaline metals from the reference aggregate equal to $255 \mathrm{~g}$ of $\mathrm{Na}$ and $159 \mathrm{~g}$ of $\mathrm{K}$ per cubic meter of concrete was estimated, corresponding to $0.79 \mathrm{~g}$ of $\mathrm{Na}$ and $0.50 \mathrm{~g}$ of $\mathrm{K}$ per $\mathrm{kg}$ of the cement paste.

In terms of alkali equivalent $\left(\mathrm{Na}_{2} \mathrm{Oeq}\right)$, these releases of alkaline metals corresponded to an alkali supply from the reference aggregate equal to $0.47 \mathrm{~kg}$ of $\mathrm{Na}_{2} \mathrm{Oeq} / \mathrm{m}^{3}$ of concrete. Such a contribution represents about $24 \%$ of the alkalis contributed by a Portland cement with an alkali content of $1.0 \% \mathrm{Na}_{2}$ Oeq. (i.e., $2.0 \mathrm{~kg}$ of $\mathrm{Na}_{2} \mathrm{Oeq} / \mathrm{m}^{3}$ for the hypothesized dam concrete composition), and therefore, it cannot be neglected at all in predicting the possible development of long-term deleterious AAR expansion in concretes made with potentially alkali-reactive aggregates.

Significant alkali contribution by Canadian aggregates to the concrete pore solution has also been reported and validated by Drolet et al. [20].

With reference to the monolithic specimens of the hydrated cement paste investigated in this study $\left(m_{0}=0.12 \mathrm{~kg}\right.$, $V_{\mathrm{m}}=0.064 \mathrm{l}$, and $V_{\mathrm{p}}=0.177 \mathrm{l}$ for CEM IV/B (P) and $V_{\mathrm{p}}=0.1591$ for CEM IV/B $\left.(\mathrm{V})\right)$ and also considering the values of $\left(C_{\mathrm{p}}^{0}\right)^{\mathrm{Na}}$ and $\left(C_{\mathrm{p}}^{0}\right)^{\mathrm{K}}$ obtained for the two types of cement paste before leaching tests (Section 4.2.1), an alkali supply equal to that of the reference aggregate $(34.3 \mathrm{mmol}$ of $\mathrm{Na} / \mathrm{kg}$ of the cement paste and $12.8 \mathrm{mmol}$ of $\mathrm{K} / \mathrm{kg}$ of the cement paste) would lead to the following concentrations of sodium and potassium ions in the pore solution: $\mathrm{Na}^{+}=0.350 \mathrm{~mol} / \mathrm{l}$ and $\mathrm{K}^{+}=0.496 \mathrm{~mol} / \mathrm{l}$ for CEM IV/B $(\mathrm{P})$ paste and $\mathrm{Na}^{+}=0.380 \mathrm{~mol} / \mathrm{l}$ and $\mathrm{K}^{+}=0.363 \mathrm{~mol} / \mathrm{l}$ for CEM IV/B (V) paste.

On the basis of these concentration values, the $M_{\mathrm{b}}$ values of Tables 7 and 8 , the values of $C_{0}^{\mathrm{K}}$ (K6 solution) and $C_{0}^{\mathrm{N}}$ (N6 solution) given in Table 3 , and also considering that $M_{\mathrm{b}}$ may increase with increasing $C_{0}^{\mathrm{N}}\left(\right.$ or $C_{0}^{\mathrm{K}}$ ), it was likely to think that hydrated CEM IV/B (V) pastes could completely bind the amounts of both sodium and potassium released by the reference aggregate, thus preventing the increase of the $\mathrm{OH}^{-}$ion concentration in the pore solution of these pastes. On the contrary, hydrated CEM IV/B (P) pastes would be able to completely bind the sodium but only partially bind the potassium released by the reference aggregate. In every case, the increase of the $\mathrm{OH}^{-}$ion concentration in the pore solution would be strongly attenuated.

\section{Conclusions}

Based on the results of this study, the following conclusions can be drawn:

(1) The proposed experimental procedure (accelerated curing of cement pastes, leaching tests on cured monolithic specimens with deionized water or $\mathrm{NaOH}$ or $\mathrm{KOH}$ solutions at different concentrations, and correlation of leaching test results with a simple mass balance equation) is appropriate for evaluating both the alkali retention capability and the pore liquid alkalinity of long-term hydrated pozzolanic cement pastes.

(2) With this procedure, a residual capability of alkali binding is identified and evaluated for each longterm hydrated pozzolanic cement paste investigated.

(3) The residual capability of alkali binding is comparable to or higher than the estimated alkali release from concrete aggregates for CEM IV/B (P) and CEM IV/B (V), respectively.

(4) The practical inference of this finding is the potential ability of such pozzolanic cements to prevent (CEM IV/B (V)) or minimize (CEM IV/B (P)) the risk of deleterious expansion development associated with alkali-aggregate reaction in long-service concrete structures, like concrete dams, for which the longterm release of alkalis from concrete aggregates could be very significant.

\section{Conflicts of Interest}

The authors declare that they have no conflicts of interest.

\section{Acknowledgments}

This work has been financed by the Research Fund for the Italian Electrical System under the contract agreement between RSE S.p.A. and the Italian Ministry of Economic Development in compliance with the Decree of March 8, 2006.

\section{References}

[1] R. Charlwood and I. Sims, "A review of the effectiveness of strategies to manage expansive chemical reactions in dams and hydro projects," in Proceedings of DSC 2017 Dam Swelling Concrete on "Swelling Concrete in Dams and Hydraulic Structures", A. Sellier, E. Grimal, S. Multon, and E. Bourdarot, Eds., Wiley-ISTE, Chambery, France, p. 380, July 2017.

[2] R. Charlwood and K. Scrivener, "Expanding concrete in dams-long term challenges" in Proceedings of the ICOLD 2011 Annual Symposium on "Dams and Reservoirs under Changing Challenges”, A. J. Schleiss and R. M. Boes, Eds., CRC Press, Lucerne, Switzerland, June 2011.

[3] R. Charlwood, K. Scrivener, and I. Sims, "Recent developments in the management of chemical expansion of concrete in dams and hydro projects-Part 1. Existing structures," in Proceedings of the Hydro 2012 International Conference on "Innovative Approaches to Global Challenges", Bilbao, Spain, October 2012.

[4] M. A. Bérubé, J. Duchesne, J. F. Dorion, and J. Rivest, "Laboratory assessment of alkali contribution by aggregates to concrete and application to concrete structures affected by alkali-silica reactivity," Cement and Concrete Research, vol. 32, no. 8, pp. 1215-1227, 2002.

[5] M. Berra, T. Mangialardi, N. Marinoni, and A. E. Paolini, "Alkali contribution by aggregates to long-term alkali-silica reaction development in concrete dams," in Proceedings of the 24th ICOLD Congress, Q. 95/R. 31, pp. 473-492, Kyoto, Japan, June 2012.

[6] I. Sims, P. J. Nixon, and B. Godart, "Eliminating alkali-aggregate reaction from long service structures," in Proceedings of the 14th 
International Conference on alkali-aggregate Reactivity in Concrete, T. Drimals, J. H. Ideker, and B. Fournier, Eds., Austin, TX, USA, May 2012.

[7] M. Berra, U. Costa, T. Mangialardi, and A. E. Paolini, “Application of an innovative methodology to assessing the alkalisilica reaction in concrete," Materials and Structures, vol. 48, no. 9, pp. 2727-2740, 2015.

[8] RILEM Technical Committee 219-ACS, "RILEM recommendations for the prevention of damage by alkali-aggregate reactions in new concrete structures," in RILEM State-of-theArt Report, P. J. Nixon and I. Sims, Eds., vol. 17, p. 168, Dordrecht, Netherlands, 2016.

[9] M. Berra, U. Costa, T. Mangialardi, A. E. Paolini, and R. Turriziani, "A new approach to assessing the performance of ASR inhibitors in concrete," Materials and Structures, vol. 46, no. 6, pp. 971-985, 2013.

[10] I. Sims, J. Nixon, B. Godard, and R. Charlwood, "Recent developments in the management of chemical expansion of concrete in dams and hydro projects-Part 2. RILEM proposals for the prevention of AAR in new dams," in Proceedings of the Hydro 2012 International Conference on "Innovative Approaches to Global Challenges", Bilbao, Spain, October 2012.

[11] M. Berra, "Concrete dams: long term behaviour and service life," in Proceedings of the Italian Concrete days, AICAP 2016 and CTE Congress on "Evoluzione e Sostenibilità delle Strutture in Calcestruzzo", Roma, Italia, October 2016, in Italian.

[12] J. Duchesne and M. A Bérubé, "Long-term effectiveness of supplementary cementing materials against alkali-silica reaction," Cement and Concrete Research, vol. 31, no. 7, pp. 1057-1063, 2001.

[13] S. Hayman, M. Thomas, N. Beaman, and P. Gilks, "Selection of an effective ASR-prevention strategy for use with a highly reactive aggregate for the reconstruction of concrete structures at Mactaquac generating station," Cement and Concrete Research, vol. 40, no. 4, pp. 605-610, 2010.

[14] T. T. H. Bach, E. Shabas, I. Pochard et al., "Retention of alkali ions by hydrated low-pH cements: mechanism and $\mathrm{Na}^{+} / \mathrm{K}^{+}$ selectivity," Cement and Concrete Research, vol. 51, pp. 14-21, 2013.

[15] UNI EN 197-1, Cement-Part 1: Composition, Specifications and Conformity Criteria for Common Cements, European Committee for Standardization, Brussels, Belgium, 2011.

[16] UNI EN 196-2, Method of Testing Cement-Part 2: Chemical Analysis of Cement, European Committee for Standardization, Brussels, Belgium, 2013.

[17] S. M. Monteagudo, A. Moragues, J. Galvéz, M. J. Casati, and E. Rejes, "The degree of hydration assessment of blended cement pastes by differential thermal and thermogravimetric analysis. Morphological evolution of the solid phases," Thermochimica Acta, vol. 592, pp. 37-51, 2014.

[18] H. F. W. Taylor, Cement Chemistry, Thomas Telford, London, UK, 2003.

[19] A. Vollpracht, B. Lothembach, R. Snellings, and J. Haufe, "The pore solution of blended cements: a review," Materials and Structures, vol. 49, no. 8, pp. 3341-3367, 2016.

[20] C. Drolet, J. Duchesne, and B. Fournier, "Validation of the alkali contribution by aggregates to the concrete pore solution," Cement and Concrete Research, vol. 98, pp. 10-23, 2017. 


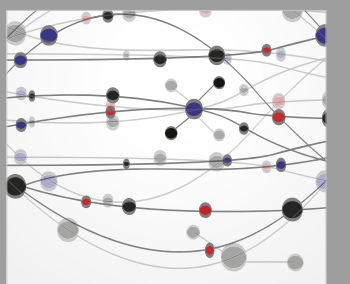

The Scientific World Journal
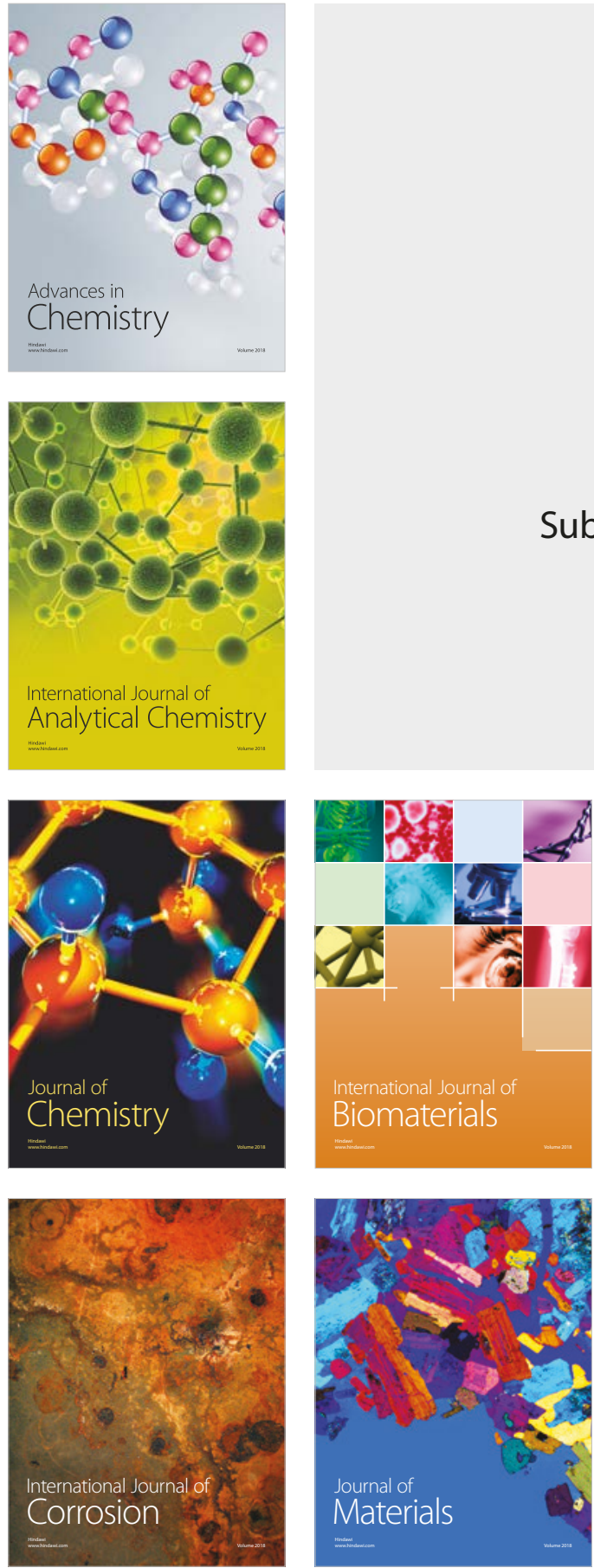

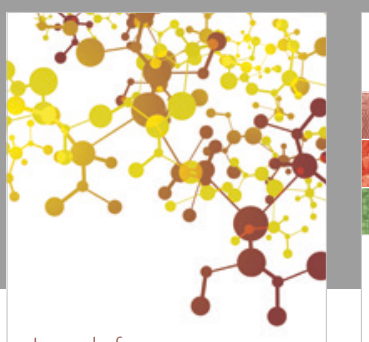

Journal of

Applied Chemistry
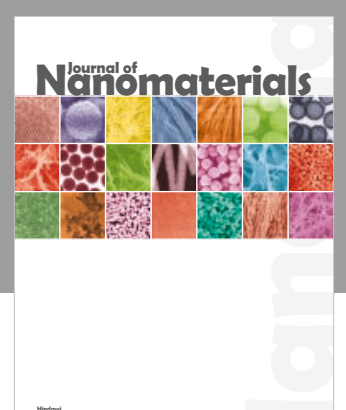

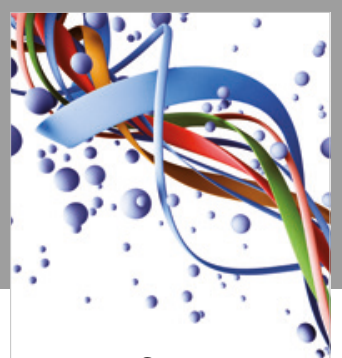

Scientifica

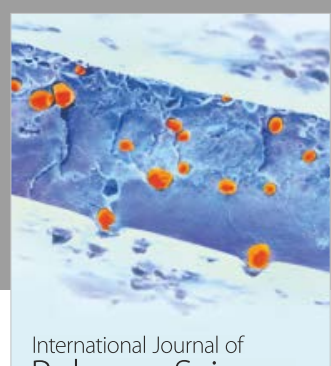

Polymer Science

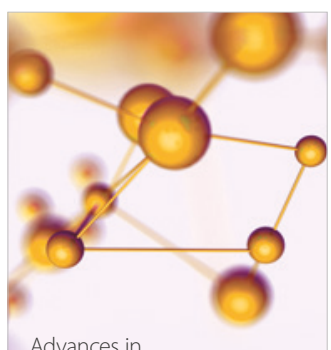

Physical Chemistry
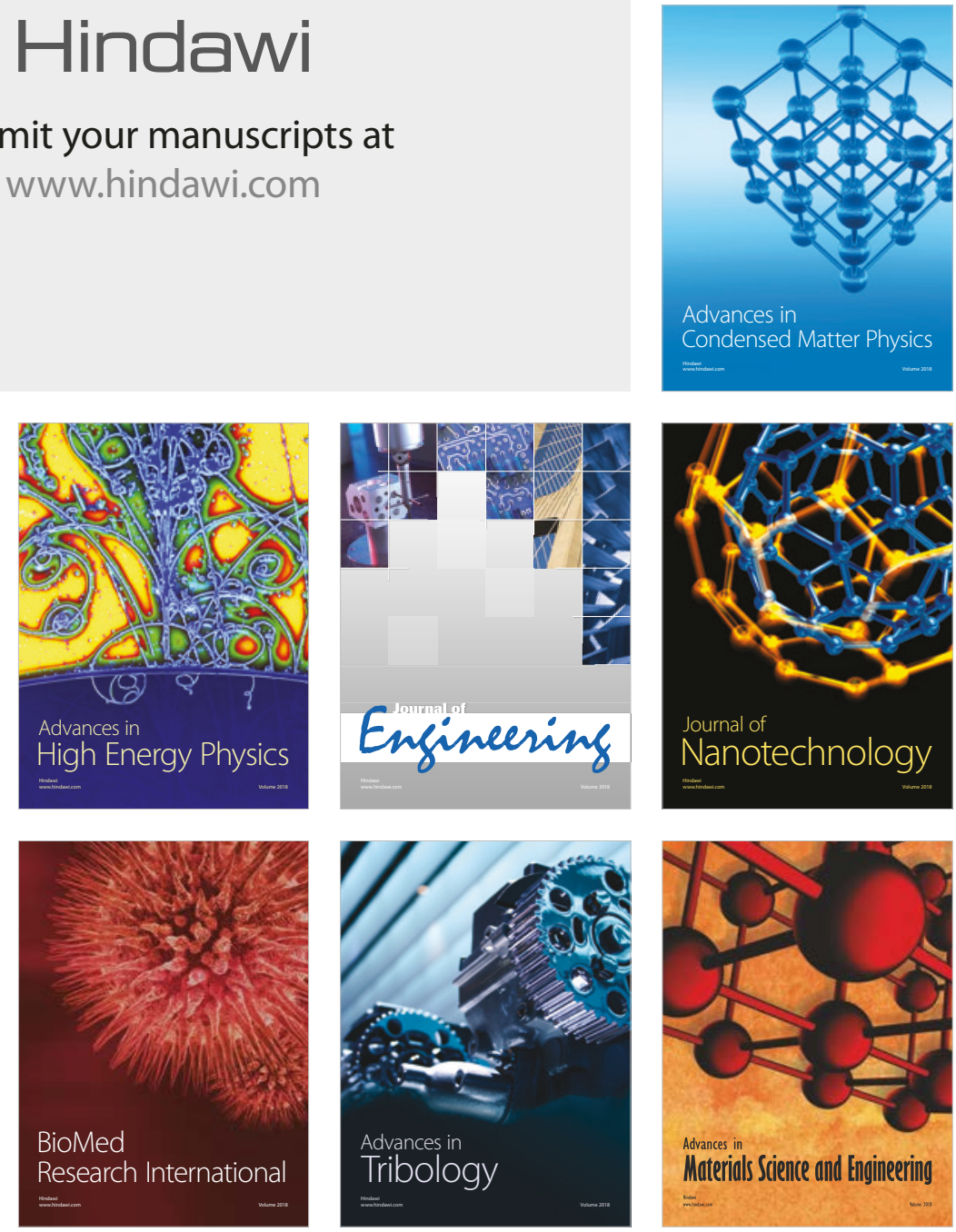